\title{
ПРОБЛЕМЫ НАЛОГООБЛОЖЕНИЯ ЭЛЕКТРОННОЙ КОММЕРЦИИ
}

\author{
Исмайылов Магсад Эльдар оглы, докторант \\ (Институт Экономики Национальной Академии Наук Азербайджана)
}

В статье проанализирована Концепция налоговой модели о доходах и капитале, вылвлены проблемы современной системы налогообложения электронной коммериии. Так в эпоху активного развития информационных технологий, интернета обостряются проблемы международного налогообложения, связанные с эрозией налогов в странах-источниках дохода, негативным эффектом налоговой конкуренщии. Раскрыты принципь налогообложения в контексте электронной коммерции, в основе которых лежит определение места эффективного менеджмента, постоянного представительства. Важным фактором при налогообложении электронной коммериии является характеристика дохода, которая позволяет доход классифицировать по таким критериям, как источник дохода («ноу-хау», предоставление услуг), оказание услуг или приобретение собственности. Выявлено, что основой пагубной налоговой конкуренции является «налоговый рай», льготные налоговые системы.

Ключевые слова: система налогообложения, электронная коммерция, транзакции, доход, налог.

\section{ПРОБЛЕМИ ОПОДАТКУВАННЯ ЕЛЕКТРОННОЇ КОМЕРЦЇ̈}

\author{
Ісмаӥлов Магсад Ельдар огли, докторант \\ (Інститут Економіки Національної Академії Наук Азербайджану)
}

У статті проаналізовано Конщепцію податкової моделі про доходи та капітал, виявлено проблеми сучасної системи оподаткування електронної комериії. Так в епоху активного розвитку інформаиійних технологій, інтернету загострюються проблеми міжнародного оподаткування, які пов'язані з ерозією податків у краӥнах-джерелах доходу, негативним ефектом податкової конкуренції. Розкрито принципи оподаткування в контексті електронної комериї, в основі яких лежить визначення місия ефективного менеджменту, постійного представництва. Важливим фактором при оподаткуванні електронної комериії є характеристика доходу, яка дозволяє дохід класифікувати за такими критеріями, як джерело доходу («ноу-хау», надання послуг), надання послуг або придбання власності. Виявлено, щуо основою згубної податкової конкуренцї̈ $є$ «податковий рай», пільгові податкові системи.

Ключові слова: система оподаткування, електронна комерція, транзакції, дохід, податок.

\section{TAX PROBLEMS OF E-COMMERCE}

\section{Ismayilov Magsad Eldar oglu, PhD \\ (Institute of Economics of the National Academy of Sciences of Azerbaijan)}

The article analyzes the concept of the model tax on income and capital, revealed problems of the modern system of taxation of electronic commerce. So in an era of active development of information technology, the Internet exacerbated the problem of international taxation related to the erosion of tax revenue source countries, the negative effects of tax competition. Explain the principle of taxation in the context of e-commerce, which are based on the definition of the place of 
effective management of a permanent establishment. An important factor in the taxation of ecommerce is a characteristic of income that allows income classified according to criteria such as source of income ("know-how", the provision of services), provision of services or purchase of property. It was found that the basis of harmful tax competition is a "tax haven", preferential tax system.

Coordinated and sustained global tax policy in the context of e-commerce is an important response to the problems of management of tax revenues. Taxation of electronic commerce should be straight in the administrative framework is not changed and non-discriminatory.

Keywords: tax system, e-commerce, transaction, income tax.

Постановка проблемы. Одним из ключевых компонентов процесса глобализации является электронная коммерция. Она как одно из самых важных экономических явлений нового тысячелетия закладывает основы нового метода введение бизнеса. Развитие информационных и коммуникационных технологий, наряду с формированием единой интегрированной информационной системы с ведущими странами мира, посредством развития внешнеэкономических отношений способствует росту качества жизни населения, их экономического благополучия. Использование электронной коммерции в развивающихся странах позволит активизировать экономический потенциал страны, т.е. стимулировать экономический рост, сокращать уровень безработицы.

По прогнозам ведущих специалистов в ближайшее будущее торговля полностью перейдет в киберпространство, что приведет к увеличению доли информационных продуктов и услуг в ВВП, созданию новой экономики - интернетэкономики. В условиях формирования новых экономических отношений одной из ключевых задач государственного управления является анализ существующей экономической системы в контексте электронной коммерции, создание налоговой системы, которая в условиях интернетэкономики позволит обеспечить необходимыми финансовыми ресурсами государственные и общественные субъекты хозяйствования.

Анализ последних публикаций и выделение не решенных вопросов общей проблемы. Вопросам налогообложения электронной коммерции, виртуальных предприятий посвящено работы многих выдающихся ученых среди которых: Корень А.В., Кеннет С., Мусайев Акиф Фархад оглы,
Гарайев Имран Алияр оглы, Балабанов И.Т., Викофф А., Colecchia А. [12-16]. Однако, в современных условиях хозяйствования, развития интернет технологий, отсутствие единых основ международного налогообложения в сфере электронной коммерции требует определения слабых мест налоговой системы, выявления принципов налогообложения, основных причин пагубной налоговой конкуренции, что позволит в дальнейшем создать действенный механизм налогообложения, разработать новые положения налоговой политики Азербайджанской Республики.

Целью статьи является исследование проблем налогообложения электронной коммерции, выявление принципов налогообложения, характеристики доходов и определения основных причин эрозии налоговой базы.

Изложение основного материала. Развитие электронной коммерции и постепенное оттеснение традиционных методов торговли обуславливают необходимость совершенствования системы налогообложения. Поскольку уникальный характер электронной коммерции, а именно, отсутствие географических границ, места проведения сделок, появление новых платежных систем, и т.п. приводят к потере налоговых поступлений в бюджет страны. Кроме того, в результате проведения международных торговых операций в силу разрозненности законодательства и налоговых систем стран налоговые органы сталкиваются с трудностями международного и государственного уровня. По мнению Организации экономического сотрудничества и развития (ОЭСР), современная налоговая система может получить убытки, которые приведут к неспособности государства выполнять свои 
социальные обязанности перед населением страны [2].

$$
\text { Фундаментальной }
$$

задачей

налогообложения электронной коммерции является определение степени привлечения электронной коммерции к налоговой ответственности. Международное сообщество пока не пришло к единому решению этого вопроса. Сначала разногласия вызвал вопрос внедрения новых специфических налогов для электронной коммерции или же освобождение ее от налогов. Но ни введение новых налогов, ни освобождение от них невозможно считать приемлемыми, поскольку приводят к уклонению от уплаты налогов, ограничению развития электронной коммерции.

Сегодня государства сталкиваются с такими проблемами международного налогообложения:

$>$ эрозия налога в странах, являющихся источником дохода;

$>$ трудности налогообложения международного финансового капитала;

$$
>\text { негативный }
$$
эффект

международной налоговой конкуренции.

Вышеуказанные

проблемы

существовали и до формирования электронной коммерции, однако развитие электронной коммерции и трансформация ее в важный сектор экономики способствовали ускорению и упрощению процессов перемещения товаров и услуг, капитала и привели к обострению данных проблем.

Принципы налогообложения в контексте электронной коммерции.

В соответствии с "Конвенцией налоговой модели о доходах и капитале" ОЭСР (Конвенция) модель налогообложения основывается на двух фундаментальных принципах [3]:

$>$ резидентство налогоплательщика;

$>$ источник дохода.

Эти принципы являются основой ряда международных налоговых соглашений, а также отражают и главные трудности процесса налогообложения электронной коммерции.

В соответствии со статьей 13.2.5.3 Налогового кодекса Азербайджанской Республики резидент - это любое юридическое лицо, зарегистрированное и осуществляющее предпринимательскую $\begin{array}{lr}\text { деятельность в } & \text { соответствии с } \\ \text { законодательством } & \text { Азербайджанской }\end{array}$

Республики или с местом управления в

Азербайджанской Республике. Под местом управления юридического лица подразумевается место основной деятельности, в котором принимаются коммерческие решения, необходимые для осуществления управления, и в котором осуществляется оперативное (ежедневное практическое) управление, вне зависимости от места размещения основных органов контроля [1].

В соответствии со статьей 4 Конвенции ОЭСР понятие "резидент" включает постоянное место жительства физического или юридического лица, место управления или любой другой критерий в этой форме [3].

Государство имеет право изымать налог на основе территориальной привязанности юридического и физического лица к этой стране. Многие государства описывают эту территориальную привязанность как "постоянное представительство" или "место управления", место «эффективного менеджмента». Концепция в целях устранения проблемы двойного резидентства для налогообложения хозяйственных субъектов предлагает рассматривать резидентство по стране, в которой находится "эффективный менеджмент". В разделе "Комментарии" к Конвенции дается объяснение понятию "эффективного менеджмента". Так, местом "эффективного менеджмента" является страна, в которой принимаются ключевые бизнес решения (Советом директоров). Хозяйственный субъект может иметь несколько мест управления, но "эффективный менеджмент" может присутствовать только в одной стране [4]. Тем не менее, развитие Интернета и телекоммуникационных технологий усложняет определение понятия "эффективного менеджмента". Поскольку руководители хозяйственного субъекта могут быть расположены в разных странах и собираться с помощью Интернета для принятия решений, a это означает расположение "эффективного менеджмента" в разных странах. Такой подход усложняет процесс определения точного 
местоположения "эффективного менеджмента". В то же время, ОЭСР опубликовало документ о изменениях "понятия о расположении эффективного менеджмента", в котором предлагает принимать во внимание ряд факторов с целью определения более четкого расположении эффективного менеджмента при современной телекоммуникационной эпохе. В зависимости от обстоятельств, эти факторы включают [5]:

$>$ если Совет директоров для регулирования деятельности хозяйственного субъекта и приятия бизнес решений собирается в одной стране, но эти решения на самом деле фактически принимаются в другой стране, то последняя страна будут рассмотрена как место "эффективного менеджмента";

если заинтересованная сторона (например, материнская компания и т.д.) осуществляет руководство и принимает бизнес решения регулирующие деятельность хозяйственного субъекта, то в таком случае местом "эффективного менеджмента" следует считать страну, в которой принимаются эти решения. Решения, принятые в таких случаях, должны быть еще более высокого уровня, чем оперативное управление и политика группы (например, конкретные решения транснациональной корпорации по деятельности каждой группы);

$>$ если Совет Директоров регулярно утверждает бизнес и стратегические решения исполнительных директоров, то при определении местоположения "эффективного менеджмента" хозяйственного субъекта важную роль будет играть место, где исполнительные директора выполняют свои должностные функции.

В случае невозможности

определения места "эффективного менеджмента" по "Концепции места эффективного менеджмента", а именно, если лица ответственные за принятие важных решений по деятельности хозяйственного субъекта регулярно собираются в разных странах и решения не принимаются в той или иной конкретной стране, или собрания проводятся с помощью современных телекоммуникационных средств, то ОЭСР предлагает использовать второй вариант определения места "эффективного менеджмента". Для этого необходимо[5]:

$>$ определить страну, к которой хозяйственный субъект имеет высшую степень экономической приверженности. Экономическая приверженность означает использование хозяйственным субъектом экономических ресурсов (количество сотрудников, активы, доходность, и т.д.), а также правовой, финансовой, физической и социальной инфраструктуры. Хозяйственный субъект считается резидентом той страны, с которой он имеет высший уровень экономической приверженности;

> определить страну, в которой хозяйственный субъект проводит основные бизнес операции. Резидентство определяется по стране, в которой проводятся важные бизнес операции;

$>$ определить страну, в которой высшее руководство хозяйственного субъекта в основном принимает решения. В этом случае, резидентство определяется по стране, в которой принимаются большое количество решений высшего руководства (например, решения президента, вицепрезидентов компании т.д.).

В то же время, по мнению ОЭСР, если невозможно определить резидентство хозяйственного субъекта в соответствии с 2м вариантом, тогда резидентство должно быть определено по стране, в которой зарегистрирован этот субъект [5].

Мобильность

электронной коммерции, которая проявляется в возможности получения доступа к серверу, который является важным элементом в управление бизнеса, способствуют получению статуса не резидента. Для государства возникают трудности с определением местоположения "эффективного менеджмента" хозяйствующего субъекта, действующего в этой сфере. Кроме того, в условиях современных телекоммуникаций, с быстрым развитием Интернета, определить в какой стране и при каких условиях принимаются решения менеджером, ответственным за важные решения хозяйствующих субъектов, становится невозможным.

При обложении налогом электронной коммерции важную роль играет источник дохода. Очевидно, что страны в пределах 
своих границ, имеют право облагать налогом нерезидентов. В связи с этим, если нерезидент имеет "постоянное представительство" в стране источника дохода, то нерезидент становится объектом налогообложения в этой стране. В соответствии со статьей 5 Конвенции ОЭСР, "постоянное представительство " может быть зарегистрировано двумя способами [3]:

$$
>\text { как постоянное место }
$$

деятельности;

$>$ посредством агента или дочерней компании.

В соответствии со статьей 19 Налогового кодекса Азербайджанской Республики, "постоянное представительство" - это место, в котором физические или юридические лица непосредственно или через уполномоченное лицо осуществляют полную или частичную предпринимательскую деятельность в Азербайджанской Республике в общей сложности не менее 90 дней в течение любых 12 месяцев [1].

Постоянное

представительство

охватывает следующее::

- место управления;

- подразделение;

- управление (контору);

- филиал и агентство;

- строительные и ремонтные площадки, монтажные или сборочные объекты, а также осуществление деятельности по контролю, связанные с подобными объектами;

- места разведки, разработки и добычи природных запасов, используемые установки или площадки, буровое оборудование или суда, а также осуществление деятельности по контролю, связанного с подобными объектами;

- база (место), используемая физическим лицом-нерезидентом для осуществления предпринимательской деятельности;

- место по оказанию различных консультационных услуг;

- рабочие места, на которых осуществляются иные виды предпринимательской деятельности на территории Азербайджанской Республики;

- лица, осуществляющие функции постоянного представительства
Азербайджанской Республике предприятийнерезидентов или физического лицанерезидента, действующие от их имени, имеющие полномочия разрабатывать или заключать договора от их имени и обычно выполняющие подобные полномочия;

$$
\text { - место производства или }
$$

предоставления товаров, выполнения работ или оказания услуг.

В тоже время, следующие виды деятельности нерезидентов не признаются деятельностью, осуществляемой через постоянное представительство:

- хранение или демонстрация предприятием-нерезидентом принадлежащих ему товаров и изделий;

хранение предприятиемнерезидентом запасов, принадлежащих ему товаров или изделий с целью их переработки и последующего вывоза из территории Азербайджанской Республики другим лицам; - приобретение товаров или заготовка изделий предприятием-нерезидентом для собственных нужд;

- осуществление предприятиемнерезидентом какой-либо подготовительной или вспомогательной деятельности для собственных нужд.

Для того чтобы адаптировать понятие "постоянное представительство" к электронной коммерции, ОЭСР подготовил документ "Уточнение концепции постоянного представительства в электронной коммерции" (дальше Изменения), чтобы внести коррективы в раздел "Комментарии" к 5-ой статьи Конвенции [6]. Изменения, касаются компьютерной техники и информации, которая хранится и используется на ней (компьютере), операционную программу. Интернет-сайт хоть и состоит из совокупности операционной системы и электронных данных, однако не является материальной собственностью, не имеет оборудования или физического местоположения, поэтому он не может определять "местоположение бизнеса" (постоянное представительство). Однако, сервер, на котором находится интернет-сайт считается оборудованием, которое имеет физическое местоположение. Это позволяет его местоположение определять как «местоположение бизнеса» предприятия, 
управляющего сервером. Следует отметить, что для того чтобы сервер стал "местоположением бизнеса", он должен оставаться в юрисдикции предприятия на некоторое время.

Постоянное представительство может иметь место даже в случае, когда для работы компьютерной техники предприятия не нужен персонал, а для выполнения полного или частичного объема работы предприятия персоналу не обязательно находиться в месте постоянного представительства.

Изменения затронули еще один важный вопрос: о подготовительных или вспомогательных работах, проводимых компьютерным оборудованием

B определенной стране, с целью проведения операции электронной коммерции. По мнению ОЭСР, при проведении таких работ "постоянное представительство" не возникает. Чтобы относить операции электронной коммерции к этой категории, нужно по отдельности рассмотреть операции, проводимые через сервер. В связи с этим, ОЭСР предлагает следующие вспомогательные или подготовительные работы [6]:

- обеспечение связи между производителем и потребителем;

- реклама товаров или услуг;

- обеспечение безопасности и эффективности передачи информации на другие сервера;

- сбор данных про рынок для предприятия;

- обеспечение

необходимой

информацией.

Если выше упомянутые функции являются основной частью деятельности предприятия и операции ведутся через постоянное компьютерное оборудование, в этом случае местоположение компьютерной техники будет определять место постоянного представительства. Основные функции деятельности компании зависят от ее бизнеса. Например, основной деятельностью Интернет Сервис Провайдера (ИСП) является управление своими серверами для обеспечения работы веб-страниц предприятий и других операционных программ. Для таких ИСП управление своими серверами является основной деятельностью предприятия, поэтому это не может считаться вспомогательной или подготовительной работой. В качестве другого примера можно показать выставление на продажу своих товаров предприятиям через веб-страницы, находящиеся на этих серверах. В этом случае, предприятие не управляет серверами. По этой причине, деятельность предприятия по месту расположения серверов может быть определена как подготовительная или вспомогательная работа. Тем не менее, необходимо анализировать процесс использования серверов по отношению к каждому предприятию. Если эти сервера используется какими-либо предприятиями для рекламы, как каталог товаров и предоставление клиентам информации о своей деятельности, тогда расположение сервера для предприятия не означает место "постоянного представительства". С другом случае, если предприятия через этот сервер заключают договор в электронном виде с потребителями и осуществляют платежи, тогда эти услуги не могут быт рассмотрены как вспомогательные или подготовительные работы.

В результате документа Изменения, страны ОЭСР договорились о ряде выше указанных вопросов. Однако, Испания и Португалия не согласны с тем, что в контексте электронной коммерции физическое присутствие следует рассматривать как требование к "постоянным представительствам"[6]. Эти страны считают, что в некоторых случаях, предприятия занимающиеся предпринимательской деятельностью с помощью веб-сайта в определенной стране могут определяется как имеющие "постоянное представительство" в этой стране.

В 5-ой статье Конвенции отмечается что, постоянное представительство в стране источника дохода может быть создано через посредника. Если посредник действует от имени предприятия и на постоянной основе имеет полномочия заключать договора от этого предприятия в стране источнике дохода, тогда эта страна будет определяться как место «постоянного представительства».

Таким образом, в соответствии с ОЭСР, место нахождения серверов являются основой при определении местоположения «постоянного представительства» в 
контексте субъектов электронной коммерции. Тем не менее, при загрузке ряда различных программ с Интернета потребителями в других юрисдикциях может быть использовано несколько серверов (например, совершение сделок, оплата и т.д.). В этом случае трудно определить местоположение постоянного представительства. В соответствии с 7-ой статьей Конвенции, страна источника дохода может облагать налогом доходы, связанные только с постоянном представительством [3]. Если сервер для предприятия нерезидента определяет место постоянного представительства, то страна источник дохода может облагать налогом доходы, связанные только с этим постоянным представительством. Чтобы определить налоговую базу, связанную с постоянным представительством, стране источника дохода нужно на индивидуальной основе подойти к каждому предприятию. Такой подход усложняет процесс налогообложения.

\section{Характеристика налогообложении коммерции. \\ дохода электронной}

Сегодня характеристика является одной из главных проблем налогообложения электронной коммерции. При характеристике доходов необходимо определять его источник и на основе этого вести идентификацию страны, которая будет иметь право облагать налогом этот доход. Электронная коммерция создает новую точку зрения при характеристике дохода, основной причиной чего является своеобразная особенность электронной коммерции. Так как реализация товаров и услуг электронным способом новые, они должны быть учтены в налоговом законодательстве.

Специальная Консультативная группа ОЭСР опубликовала доклад о "Характеристике доходов налоговой конвенции связанный с электронной коммерцией" [7]. Доклад играет важную роль для достижения международного соглашения по характеристике доходов и имеет предложения по изменениям в разделе "Комментарии". Одним из обсуждаемых вопросов в докладе является различение дохода от предпринимательской деятельности и роялти в контексте электронной коммерции (загрузки электронных продуктов). Группа делит транзакции по загрузке электронных продукты (программное обеспечение, картинки, музыка или текст) на две отдельные категории. К первой категории относятся транзакции по электронным продуктам, загруженные потребителями для личного пользования или развлечения. При осуществлении таких транзакций сущностью платежей является использование электронных продуктов для личного использования или развлечения. Такие выплаты характеризуется как доход от предпринимательской деятельности, а не роялти. Загрузка электронных продуктов на цифровые устройства потребителей по законодательству считается использованием авторских прав, но в данном случае этот процесс является случайностью. Такая случайность же не становится важным фактором при характеристике дохода. Потому что, как уже отмечалось, назначение платежа является личное использование электронных продуктов. Ко второй категории относятся транзакции с назначением платежа с переходом авторского права на электронный продукт. Такие транзакции со специальным классифицируются как роялти.

Другой вопрос, упомянутый консультативной группой в докладе, это разделение платежей на снабжение ноу-хау и предоставление услуг. Из-за трудностей, возникающих в практике при разделении этих платежей, Группа предлагает принять во внимание следующие ключевые элементы:

$>$ контракты на поставку ноу-хау объединяют уже существующую информацию по его созданию, включают положения о конфиденциальности этой информации;

$>$ в контрактах на предоставление услуг, поставщик обязуется оказывать определенные услуги. Для этого от поставщика не требуется передачи конкретных знаний, умений и опыта другому лицу, а только использование этих знаний, навыков и опыта.

Во многих случаях, в соответствии с соглашением при поставке "ноу-хау" предприятия имеют меньше дополнительных расходов, чем во время предоставления услуг 
по обеспечению существующей информации или производства материала поставщиком.

В качестве примера платежей за предоставление услуг можно показать следующее[7]:

$>$ плата за послепродажное

обслуживание;

$>$ платежи за услуги,

предоставляемые продавцом покупателю в рамках гарантии;

помощь;

$>$ платежи за полную техническую

$>$ платежи инженеру, юристу или бухгалтеру за услуги консультации по определенным вопросам;

$>$ платежи за предоставление электронной консультации, доступа к технике для решения проблем, в базы данных путем электронных коммуникаций или по компьютерным сетям.

В деловой практике, в контрактах встречаются статьи и про ноу-хау, и про техническую помощь. Одним из примеров является договор по франчайзингу. В таких соглашениях в дополнение к передаче своих знаний и опыта франчайзер также оказывает техническую помощь. В таких смешанных формах соглашений разумным является подход к договору, который делит его на различные части (ноу-хау и услуги). После этого, следует применять соответствующий механизм налогообложения для каждой части [7].

Одним из самых важных моментов в докладе является разделение оказания услуг и приобретение собственности. Поскольку разделение этих типов платежей важны для ряда двусторонних конвенций, а также для целей внутреннего налогообложения. Главной отличительной особенностью транзакций по оказании услуг и приобретению имущества, является точное определение цели платежа. Если потребитель после выполненной транзакции становится владельцем важной собственности, но собственность не приобретена у поставщика, то это должно интерпретироваться как транзакция по оказанию услуг. Если первая сторона дает заказ второй стороне создать какой-либо объект собственности (например, создание специального доклада) и объект после создания останется во владении первой стороны, то такую сделку следует характеризовать не как транзакция по приобретению имущества, а как транзакция по оказанию услуг. С другой стороны, если покупатель приобретает специально подготовленный для него доклад или объект собственности (например, продажа высшей ценности инвестиционного доклада нескольким покупателям), то такая транзакция должна считаться как приобретение собственности [7]. В то же время, если в назначении транзакции предоставление услуг занимает доминирующее положение (приобретение собственности выступает в качестве вспомогательного), то такая сделка должна быть включена в категорию предоставление услуг. В основном такие условия создаются, когда у объекта собственности меньше внутренней ценности и эта ценность создается за счет собственных специальных навыков и умений поставщика. Например, "онлайн" консультации или другие профессиональные услуги, будучи транзакциями электронной коммерции, относятся к прибыли, полученной от предоставления услуг.

\section{Пагубная налоговая конкуренция в сфере электронной торговли (эрозия налоговой базы).}

Транзакции, проведенные между странами, создают благоприятные условия для уклонения от уплаты налогов. Для этого используется множество разных методов. Проблемы уклонения от уплаты налогов, возникающие в результате развития мировой экономики, становятся серьезной угрозой для налоговых органов страны. Высокая мобильность и развитие интернет-технологий обуславливают возникновение и использование так называемых транзакций «налоговый рай». А это в свою очередь приводит к эрозии налоговой базы. Эрозия налоговой базы может принять формы: законное уклонение от оплаты налогов или незаконное уклонение от налогов. Например, уклонение или же неуплата налогов может осуществляться переводом налогооблагаемой предпринимательской деятельности в другие юрисдикции. Изменения, происходящие в технологиях и либерализация финансовых операций, расширили сферу уклонения от налогов и их неуплату. Таким образом, бизнес функции могут перевестись в 
юрисдикции с низким налоговым тарифом, а банковские счета в «оффшорные» зоны. Если для предпринимательской деятельности используются только компьютер, связь и модем, то эта же деятельность может быть переведена в любое местоположение. А это создает налоговым органам трудности в привлечении к налоговой ответственности этих хозяйственных субъектов. Своеобразная особенность интернета для многих транзакций создает возможности выступать как «налоговый рай» (особенно в контексте электронной торговли).

Однако, одной из главных организацией, деятельность которой направлена на решение проблем пагубной налоговой конкуренции является ОЭСР. В связи с этим ОЭСР в 1998 году опубликовала отчет «Пагубная налоговая конкуренция: формировавшее глобальное явление» [9]. В отчете в качестве основных элементов налоговой конкуренции были представлены: налоговый рай и льготные налоговые режимы. В контексте электронной торговли применение на доходы, полученные от мобильных транзакций, низкой налоговой ставки, по сравнению с эффективными налоговыми ставками других стран, налогового рая и льготного налогового режима может привести к отрицательным последствиям, а именно:

- искажению финансовых реальных инвестиционных потоков;

- попаданию под подозрение честности и справедливости налоговой структуры;

- $\quad$ стремлению налогоплательщиков к уклонению от уплаты налогов;

- реформированию разнообразия и желаемого уровня налогов и общественных расходов;

- направлению налоговой нагрузки на труд, потребление и недвижимость как на менее мобильные налоговые базы.

- увеличению административных затрат и налоговых нагрузок налоговых органов и налогоплательщиков.

Налоговые юрисдикции с выше упомянутыми негативными эффектами считаются пагубными. Если такие налоговые практики оказывают значимое влияние на налоговые базы других стран, то налоговая практика, осуществляемая в такой форме, относится «к пагубной налоговой конкуренции». Даже при трудностях определения нежелаемого экономического влияния, он может быть пагубным. Например, для анализа экономической эффективности режима отсутствие таких требований, как годовой оборот необходимых счетов, идентификация бенефициаров и другой подобной информации ставит налоговую прозрачность под сомнение. При невозможности измерения экономических потерь, эти режимы должны считаться пагубными со стороны соответствующих стран.

Некоторые страны проводят мягкую налоговую политику или полностью освобождают субъекты хозяйствования от налогов с целью привлечения финансового капитала. Также к такой политике относятся привлекательность нормативной и административной базы. Выделяют и такую юрисдикцию, как «налоговый рай». В основном налоговый рай служит 3 целям [9]:

$\checkmark$ место для сохранения пассивных инвестиций («хранение»);

$\checkmark$ место хранения нереализованных доходов («доход на бумаге»);

$\checkmark$ предотвращение

проверки

налоговыми органами других стран счетов налогоплательщиков.

Эти функции обладают потенциалом нанесения ущерба налоговым органам других стран. Потому что эти налоговые органы создают условия для уклонения от налогов.

В своем отчете ОЭСР верифицирует налоговый рай на основе ниже приведенных признаков [9]:

$>$ применение налогов в номинальной сумме или же отсутствие налогов;

отсутствие эффективного обмена информации. Обычно в «налоговом рае» имеются серьезный закон о конфиденциальности и административные правила;

$>$ отсутствие прозрачности;

отсутствие значимой деятельности в этих юрисдикциях.

Ряд стран для привлечения мобильных финансовых операций применяют систему льготных налогов. Такие режимы могут быть регулированы специальным законодательством, в 
налоговом кодексе или в неналоговой системе. В отчете были показаны 4 основные фактора, характеризующие льготные налоговые системы [9]:

отсутствие низкой и эффективной налоговой ставки;

$>$ разграничение налогового режима.

Ряд стран, предлагающие льготные налоговые режимы, держат этот режим за пределами своего внутреннего рынка. Для защиты своей экономики от льготного налогового режима страны определяют границы, это происходит из-за потенциальности пагубности режима. Ограничение можно достичь несколькими способами:

$\checkmark$ предотвращение выгод от преимущества режима со стороны резидентналогоплательщиков;

\section{$\checkmark$ предотвращение}

функционирования

хозяйствующих

субъектов, во внутреннем рынке, которые пользуются преимуществами режима;

$>$ отсутствие

прозрачности.

Отсутствие прозрачности в проведенных транзакциях затрудняет осуществление мер защиты в других странах. Непрозрачность отражается в законах и подзаконных актов;

$>$ отсутствие эффективного обмена информацией. Один из самых важных инструментов в определении, является ли режим пагубным или нет - реализация эффективного обмена информацией между странами.

В своем докладе ОЭСР также предоставляет ряд защитных механизмов от "налогового рая" и льготных налоговых режимов. Следует отметить, что позиция ОЭСР оценивается низко налоговыми юрисдикциями противоречиво. Так как развитые страны в основном применяют высокие налоговые ставки, они не заинтересованы в том, что бы юристикции с низким уровнем налогообложения в дальнейшем реализовывали такую политику. В то же время, некоторые эксперты считают, что ОЭСР выступает от принципов традиционного международного налогообложения.

Выводы. Огромный потенциал электронной коммерции и развитие в современных условиях представляют угрозу для нормального функционирования

налоговой системы, но в то, же время открывают новые возможности для развития бизнеса. Вышеупомянутая функция делает предвзятым роль государства в экономике. Кроме того, усиление контроля над электронной коммерцией ограничивает условия, необходимые для ее функционирования (существование гиперпространства, не ограничиваемого границами государств; использование современных технологий для обеспечения безопасности сделок и т.д.).

Скоординированная и устойчивая глобальная налоговая политика в контексте электронной коммерции является важным ответом на проблемы управления налоговыми поступлениями. Налогообложение электронной коммерции должно быть прямым в административных рамках, неизмененным и недискриминационным.

Таким образом, учитывая выше упомянутое, становится ясным фискальный интерес стран в сфере электронной коммерции. Налоги являются важнейшим инструментом экономической политики. Функциональность налоговой системы на должном уровне кроме обеспечения стабильности государственного бюджета, создает благоприятные условия для развития частного предпринимательства и государственного сектора, позволяет обеспечить справедливое распределение доходов в обществе.

Поэтому, наличие должного механизма налогообложения электронной коммерции, учитывающего его характеристики, может превратить эту область в стабильный источника налога.

\section{СПИСОК ЛИТЕРАТУРЫ}

\section{1. Налоговый}

Азербайджанской resource]. http://online.zakon.kz/Document/?doc_id=30414 629

2. Harmful tax competition An Emerging Global Issue [Electron resource]. Access Mode: http://www.oecd.org/tax/transparency/44430243 .pdf 
3. Model convention with respect to taxes on income and on capital [Electron resource]. - Access Mode: http://www.oecd.org/ctp/treaties/2014-modeltax-convention-articles.pdf

4. Model Tax Convention on Income and on Capital: Condensed Version 2014 [Electron resource]. - Access Mode: http://www.keepeek.com/Digital-Asset-

Management/oecd/taxation/model-taxconvention-on-income-and-on-capitalcondensed-version-2014_mtc_cond-2014en\#page92

5. Place of effective management concept: suggestions for changes to the oecd model tax convention [Electron resource]. Access Mode: http://www.oecd.org/tax/treaties/2956428.pdf

6. Clarification on the application of the permanent establishment definition in ecommerce: changes to the commentary on the model tax convention on article 5 [Electron resource]. - Access Mode: http://www.oecd.org/tax/treaties/1923380.pdf

7. Tax treaty characterisation issues arising from e-commerce report to working party no. 1 of the oecd committee on fiscal affairs [Electron resource]. - Access Mode: http://www.oecd.org/tax/consumption/1923396. pdf

8. Electronic commerce and tax base erosion [Electron resource]. - Access Mode: http://www.europarl.europa.eu/RegData/etudes/e tudes/join/1999/168015/DG-4ECON_ET\%281999\%29168015_EN.pdf
9. Harmful tax competition An Emerging Global Issue [Electron resource]. Access Mode: http://www.oecd.org/tax/transparency/44430243 .pdf

10. Are the Current Treaty Rules of Taxing Dusiness Profits Appropriate for ECommerce [Electron resource]. - Access Mode: http://www.oecd.org/tax/treaties/35869032.pdf

11.The OECD Harmful Tax Competition Report: A Tenth Anniversary Retrospective [Electron resource]. - Access Mode: http://repository.law.umich.edu/cgi/viewcontent. cgi? article $=1037 \&$ context $=$ articles

12.Корень А.В. Налогообложение субъектов электронной коммерции: проблемы и перспективы: монография / А.В. Корень. - Владивосток: Изд-во ВГУЭС, 2010. - $176 \mathrm{c}$.

13.Kenneth C. Laudon and Carol GuercioTraver. (2009). "E-Commerce: Business, Technology, and Society", Prentice Hall,. (Kenez S. Laudonva Karol GersioTraver (2009).

14.Musayev Akif Forhad oğlu və Qarayev İmran Oliyar oğlu. "Elektron Kommersiya və Vergitutma". Azərbaycanın vergi jurnalı. Mart Aprel, 2013-cü il, №2. - səh. 65-82.

15.Балабанов И.Т. Электронная коммерция./ И.Т. Балабанов СПб: Питер, 2001. -336 с.

16. Wyckoff A. The Economic and Social Impact of Electronic Commerce / A.Wyckoff, A. Colecchia . - Paperback - March 1, 1999. - $169 \mathrm{p}$.

Рецензент д.э.н., профессор УкрГУЖТ Кирдина Е.Г. Эксперт редакционной коллегии к.э.н., доцент УкрГУЖТ Полякова Е.Н. 